Authors' post-print (final draft post-refereeing)

To be published as:

Jellema, P., Annemans, M., Heylighen, A. (2018). At Home in the Hospital and Hospitalized at Home: Exploring Experiences of Cancer Care Environments. In: Langdon P., Lazar J., Heylighen A., Dong H. (Eds.), Breaking Down Barriers - Usability, Accessibility and Inclusive Design. Springer.

Please refer to the publisher's final version. 


\title{
At Home in the Hospital and Hospitalized at Home: Exploring Experiences of Cancer Care Environments
}

\author{
P. Jellema, M. Annemans and A. Heylighen
}

\begin{abstract}
Contemporary cancer care takes place within a healthcare system catering for a highly mobile demographic. This study aimed to better understand how patients experience the cancer care environment (CCE) and the role of spatial aspects therein. We explore the effectiveness of photovoice in discussing this experience over time and the extent to which image production helps emphasize the role of spatial aspects. Three patients were interviewed over the course of six weeks. Experiences of the CCE turned out to change over time and across space as repeated travel to the hospital and transitions within the hospital resulted in new impressions and routines. Participants describe the dynamic and linked makeup of the CCE, suggesting a concatenation of places over time. The photovoice method blurs the boundary between researcher and participant, allowing features of the CCE to come to the fore that would otherwise not be considered. Over time, the hospital becomes 'a second home' to some, facilitating more than medical consultations and treatments only. A particular challenge for hospital design is therefore to improve the initial experience. Simultaneously, the home environment becomes a place of medical care at a distance. Caution is required when transforming the home into such a place as patients can feel insecure and distant from the watchful eye of the specialists.
\end{abstract}

\section{Introduction}

Architecture is increasingly recognised to impact on people's well-being and quality of life (Jencks 2012; Sternberg 2009). Furthermore, there is a growing understanding of, and supporting evidence for, the role architectural design plays in the creation of 'wholesome' healthcare environments. Especially in cancer care facilities, where people are confronted with stress and anxiety, exploiting architecture's potential is highly relevant. Examples such as the UK-based Maggie's Cancer Care Centres demonstrate that high-quality architecture is not an expensive luxury but the context responsible for quality of life and well-being. The buildings convey an encouraging and supportive message to all who enter. Studies suggest that designing buildings with people's emotional needs in mind can lift their spirits and support the care offered on multiple levels (Annemans et al. 2012; Van der Linden et al. 2015): by generating a feeling of identification; by affording different uses and atmospheres;

Pleuntje Jellema, pleuntje.jellema@kuleuven.be ,

Margo Annemans margo.annemans@kuleuven.be and

Ann Heylighen ann.heylighen@kuleuven.be

KU Leuven, Dept. of Architecture, Research[x]Design 
and ultimately, by supporting social interaction between its users and those around them, without forcing it upon them. However, distinct differences exist between the Maggie's Centres, offering psychosocial support, and the Cancer Care Environments (CCEs) that focus primarily on medical care. This study starts from the observation that the experience of people affected by cancer is not sufficiently taken into account in the design of environments where treatments and consultations take place.

This raises the question how people can be supported in expressing their experience of these environments. Using participant-made photographs within interviews has helped researchers to reveal experiences that are difficult to express or too abstract (Frith and Harcourt 2007; Radley 2010). It is additionally found to benefit the relationship between the researcher and a patient participant (Radley 2010). Namely within community based participatory research photovoice has been used to identify spatial aspects of experience, often at the scale of a neighbourhood (Wang and Burris 1997). Using photovoice explicitly to integrate participant agency into the research procedure is less common where it concerns user experience of a particular health care environment. In part this may be context-related, where taking photographs is not common or may be considered inappropriate due to privacy concerns.

In this study, we explore to what extent photovoice can be used to engage people affected by cancer in investigating how spatial aspects affect their experience while also taking into account the sensitive nature of the CCE as a context to conduct research in. Ultimately, our aim is to gain a better understanding of how people affected by cancer experience the CCE and the role of spatial aspects in this experience.

\section{Context}

In care practice, considerable efforts are made to avoid an institutional atmosphere and create CCEs that express hospitality. This trend can be observed in hospitals and oncology wards, in cancer care centres, in accommodations of peer support groups, and palliative care centres. However, realising a hospitable CCE is not straightforward, for either the care organisations or architects. Since stress and anxiety are context- and person-specific, designing for people affected by cancer requires taking into consideration their particular concerns, wishes and experiences (Annemans et al. 2012; Huisman et al. 2012). In studies about the impact of the built environment on people's well-being and quality of life, these are hardly addressed. Research in Evidence-Based Design predominantly examines the effects of isolated aspects (e.g., daylight, a view on green (Ulrich 1984)) on people's primary clinical reactions, without addressing their opinions, ideas, and views (Malkin 2006). Moreover, by focussing on a single aspect (Rubin, Owens, and Golden 1998), these studies fail to consider the outcomes holistically (Huisman et al. 2012), and invariably conclude that the findings cannot readily inform the design of care facilities (Kirkeby 2015; Lawson and Parnell 2015). 


\section{Method}

Through the use of ethnographic methods, this study attempts to identify common threads in how the CCE is experienced by cancer patients and spatial aspects that play a role in that experience. By combining photovoice with semi-structured interviews we see knowledge as created in interaction between the researcher and the participants (Guba and Lincoln 1994). Due to the exploratory nature of the study, participants who met pre-determined selection criteria were approached through convenience sampling. We explore how the CCE is experienced by the following research participants:

Lisa, a 37 year old female, was diagnosed with cancer, underwent an amputation followed by six months of chemotherapy. At the time of the interviews she was receiving radiotherapy. She lives with her husband, a daughter of 12 years old and numerous pets.

Helen, a 57 year old female, underwent an operation, chemotherapy and radiotherapy. At the time of meeting she was receiving adjuvant therapy and rehabilitation physiotherapy. She was treated in a regional hospital, which offered radiotherapy through a collaboration with another hospital. While on holiday she went to yet another hospital. She lives with her husband and a pet dog.

Walter, a 67 year old male, has been confronted with different types of cancer over the past few years. Most of his cancer care has taken place in the same hospital as Lisa, although different campus buildings feature in his accounts. He received chemo, both as an in- and as an outpatient. He also underwent multiple radiotherapy treatments. He and his wife recently downsized to an apartment.

Participants agreed to be interviewed at their home. Before commencing they were made fully aware of the aims of the study, the researchers involved and how the data were going to be collected and saved. An informed consent form was presented and signed and practicalities regarding the study were discussed. The form included supplementary information, a copy of which was left with the participant. The interview was audio-recorded and structured according to a topic list. After this interview the participants were asked to visually document their experiences of the CCE during (one of) their next appointments. To take photos they were offered the choice of borrowing a device or using their own. A selection of the photos was emailed to the first author in preparation of a follow-up interview. This process was repeated two more times with Helen and Lisa. For various reasons Walter was not able to take photographs. Our findings are based on an in-depth study of Lisa and Helen's material supplemented with the analysis of Walter's interview material.

Interviews were transcribed verbatim interspersing the text with photographs when these were being discussed. The analysis of interview transcriptions was done following the guidelines of the QUAGOL method based on the constant comparative method of grounded theory (Dierckx de Casterlé et al. 2012). The anonymity of the participants was ensured throughout (e.g. by anonymising photos and using pseudonyms in dissemination). Although the hospitals are not named within the study, it is impossible to guarantee their anonymity as the infrastructure is recorded in some of the photographs. 


\section{P. Jellema et al.}

\section{Experiencing the Cancer Care Environment}

Through participants' verbal description and visual depiction of their experience over time, and its intertwinement with emotional and social aspects, their exposure to the CCE becomes more clear. How their experiences change over time and across space offers insight into the CCE as a dynamic and linked entity. Our focus is on the participants' experience as long-term outpatients even though their treatment has included a hospital-stay at some point.

\subsection{Home, transit and hospital}

Gaining a sense of the 'places of importance' that the CCE is comprised of, from the participants' perspective, meant asking questions about what locations and movements were involved. A pattern emerges of cancer care taking place in different locations: a sequence of spaces and places that merge in and out of the individual's experience. As participants go through a course of treatment, different spatial aspects take on prominence. In both photographs and interviews, the hospital, home, and other places have roles to play. All three participants find a sense of safety and comfort important. Sometimes this leads to the hospital being spoken about as a "second home". At the same time, by being asked to document their experience of the CCE, participants are able to put forward the idea that the home environment is, in its own way, also part of the CCE. To avoid confusion regarding this definition results will be discussed referring to the hospital and the home.

The hospital is rarely talked about as being one place or building. It consists of different places, and places within places. An initial experience of a particular setting or destination will linger in one's memory, be built upon and referred back to. The size, colours, furnishings, and amenities contribute to the general atmosphere. Participants indicate their sensitivity towards the lighting, temperature, acoustics, odours and ventilation. The atmosphere is regularly compared to their idea, or image, of a 'typical hospital' (figure 1). It is also affected by the cadence, i.e., the busyness or occupancy of the space at a particular moment, and by challenging indoor routes or difficulties understanding the wayfinding signage. A period of cancer treatments is characterised by a string of initial impressions as they are directed to spaces for the first time. A sequence of spaces is the result. Some are left behind, while others are returned to repeatedly.

$$
\begin{aligned}
& \text { Because of that bad experience... and because of the bad news that you received } \\
& \text { there ... I really... yeah, that took a very long time before I was brave enough } \\
& \text { to go in there again. } \\
& \text { (Interview Lisa) }
\end{aligned}
$$

As participants become accustomed to the place, there is then attention for what the environment has to offer and affords. Art in the hospital is a welcome distraction, as is the perceived connection with outdoor nature. Furniture is important, as well as being able to get a drink, or take in information about treatments or support-related services. Walter and his wife find it convenient that they know where they can find a blanket when necessary. Lisa wants to be able to use personal devices for 
entertainment and household related activities. She likes the curtains that she can close around her while receiving chemotherapy treatments (although Walter claims no-one uses these because the remaining space is too cramped). Lisa also appreciates jigsaw puzzles that are provided in the radiotherapy waiting areas.

Some actions only become possible when one feels sufficiently at ease. Helen considers the gym a good place for people to take off their wig (figure 2): in that setting it was necessary (hot and sweaty) and possible (generally supportive) to do that.

$$
\begin{aligned}
& \text { It's a really big step to enter into that confrontation with other people. If you } \\
& \text { can do that there, then afterwards it will be easier with family and friends. So, } \\
& \text { that's a place to do that. } \\
& \text { (Interview Helen) }
\end{aligned}
$$

Participants eventually lay claim on (a piece of) the hospital. Lisa calls the oncology outpatient centre her 'second home'. She emphasises the transition between the typical hospital environment and 'her world' on the other side of the door where she receives chemotherapy. It is as though the door says 'welcome' by automatically opening, outwards, towards her:

$$
\begin{aligned}
& \text { It's like a boundary you have to step over. And when those doors open ... It's } \\
& \text { like... they come towards me those doors, as though they say 'welcome, come } \\
& \text { in, come into this world'. } \\
& \text { (Interview Lisa) }
\end{aligned}
$$

Different phases of treatment occur in different places, and as participants become more accustomed to a place and route, their needs and expectations evolve. Spatial aspects can be identified at different scales. The atmosphere at the time of the initial diagnosis sticks in one's memory. Key features of the environment get intertwined with other memories of the experience. A string of initial impressions and memories of the CCE are formed throughout the period of treatment. The environment is experienced as being supportive when patients can show initiative or exert some control there.
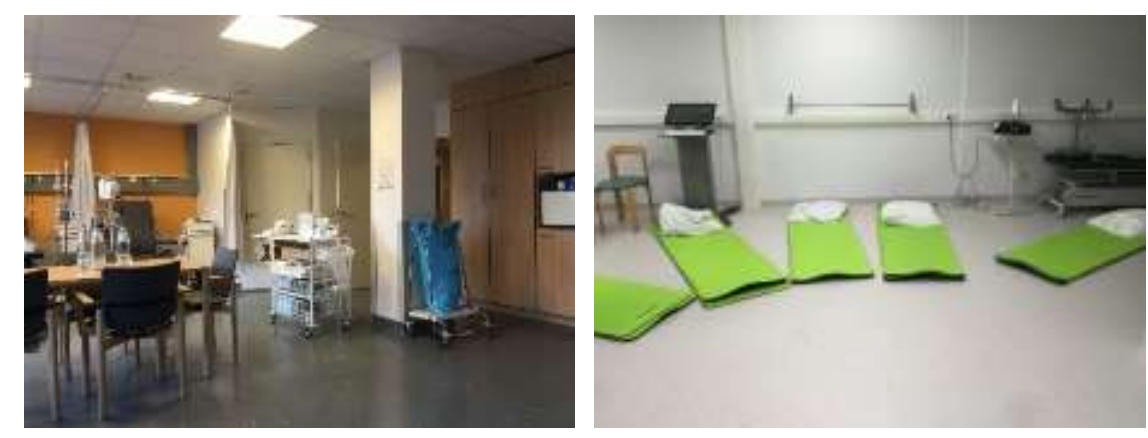

Fig. 1 (left) Helen accepts this type of space with mixed feelings: "really hospital-like"

Fig. 2 (right) Helen describes a gym space with green mats: "happy colours, a great space"

Experiences of transit, both within hospital buildings and on the way to the hospital, are described by all participants. The spatial aspects that become apparent in these experiences are intricately linked to changes over time. Throughout a period 
of treatment an awareness of time is apparent at different 'scales'. Firstly, participants recount a personal motion through the period of illness and treatment. Secondly, the temporal comes up in the (repeated) experience of single hospital visits. How often one has been to a place makes a difference. Different types of treatment require different rhythms in terms of the regularity of hospital visits. As familiarity with a space increases initial feelings of fear and stress are replaced with a sense of safety and routine. When the general experience of a place is positive it is perceived as reliable and stable. Walter, looking back on at least 112 separate hospital visits for cancer care, summarises it as follows:

The hospital for me is always... Yeah, it's there. I don't have any problems with it. I don't know how better to say that. Yes, we go to the clinic. I know my way round there. (Interview Walter)

Negative aspects of routines also surface. For example, Lisa describes being infuriated each time she has to pass by an ashtray outside the entrance to the oncology wing.

The convenience of 'being nearby', particularly in relation to the repetitive nature of hospital visits, contrasts with long distances walked within the hospital. There is an explicit appreciation for designated parking areas, near to entrances, allowing easy access. Appreciation (or frustration) is most often expressed about aspects of spatial organisation that relate to convenience and privacy. The participants notice when their interests and limitations are acknowledged (or not). As the route and place become more familiar, new habits emerge. Going 'there' and home again is described as happening in a certain way. Especially for Lisa, stopping for coffee became a cherished habit (figure 3). Both Lisa and Walter were usually accompanied by significant others. Helen was more independent in this respect.
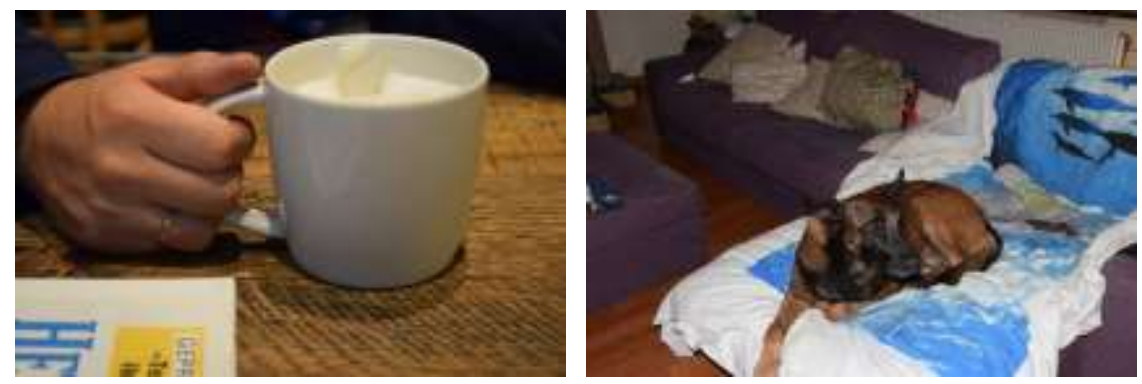

Fig. 3 (left) Lisa and her husband stop for coffee: "Our moment of relaxation"

Fig. 4 (right) Lisa talking about the dog: "At home, my consolation when I'm alone"

The importance and comfort of the home is emphasized in relation to repeated travel to the hospital. It is generally a supportive environment. Family members and pets play a role in this (figure 4). The sofa is an important place to rest. Lying in bed seems to make one feel even sicker (both in the hospital and at home). Helen prefers having people visit her at home rather than in the hospital. Lisa refers to her home as 'her cocoon': 


\section{P. Jellema et al.}

Here you can hang around, lie down and do whatever you like. If I'd go somewhere I'd have to wear something other than my pyjama's. Or at home I'd take off the headscarf every now and then. Somewhere else I wouldn't do that. Here in my cocoon I always feel [takes deep breath] ... $\quad$ (Interview Lisa)

However, Helen describes the home as also a place of feeling unsure and invisible. Her days there were some of the worst. She would feel incredibly ill and not know what medication to take. She associates a particular corner in the living room with these bad days. Walter and his wife recently moved from a large home that was becoming too much to deal with.

\subsection{As a result of treatment}

How the CCE is experienced, and the role of spatial aspects therein, turns out to be considerably affected by the cancer treatment. Firstly, the changing body interferes with routines and takes one by surprise. Feeling sick, tired, changed in terms of appearance, or sensory perception has people relate differently to their environment (sometimes suddenly) than if they were relying on a more healthy body. One clear example is the distance one can walk before needing to rest. Walter describes a situation after being in hospital for a five-day chemo treatment:

$$
\begin{aligned}
& \text { My wife was coming to pick me up. Me and my suitcase. And then I do find the } \\
& \text { oncology department really far to go on foot. In fact I find it a bit far. With my } \\
& \text { suitcase, after packing everything I was fine. But then on the way it was like } \\
& \text { being knocked with a hammer. Just so tired, tired, tired. (Interview Walter) }
\end{aligned}
$$

The changing body as a result of illness or medical procedures can result in feelings of helplessness. Helen describes a situation where a fellow patient had been warned to stay away from young children and pregnant women due to the radioactive medication she had been given. Subsequently, she had an appointment with a gynaecologist and found waiting in a room with pregnant women confronting and difficult. Lisa was challenged by the complete lack of privacy when she was in a full waiting room while really wanting a private moment to cry.

The second theme relates to social interactions, with staff, family and fellow patients. The hospital plays a role in facilitating these interactions. At the same time it is described as a place where the participants are confronted with other patients, a type of interaction that is forced and uncomfortable. Lisa points out that talking to healthcare support staff was only possible after explicitly requesting an appointment. She also found access to fellow patients limited and mostly activity-based. Opportunities to connect with people in a similar situation were scheduled occasions and not always available at a time and place that suited her. Walter's partner played a key role in supporting social interactions. Helen seemed to connect with fellow patients more spontaneously. She appreciated sharing a room, emphasising that she had more in common with that roommate than with a friend who visited while she was receiving chemotherapy. She describes the way conversations start based on small gestures and non-verbal contact when the space allowed for a certain proximity:

You saw the other man glancing over, he looked, nodded, hello sir and then I thought yeah, a comment, you know something you say as a joke about what he 


\section{P. Jellema et al.}

did and then our conversation was launched ... Partly that is about who I am but it's also a space for that. You're sitting close to each other the whole time and you can read a book or you can do what you like, it's the same. But sometimes it's fun to say something.

(interview Helen)

Additionally, participants touch on the topic of shame and stigma. They point out difficulties around communicating about cancer both with people who are familiar and with people who are un-familiar to them. Consider the account of patients putting on a wig to cross a parking lot to then arrive in the gym where they promptly remove it. Helen talks about avoiding eye-contact with an acquaintance on her way to having her breast amputated because she finds this experience more challenging to talk about than when she previously had surgery. There is, therefore, a need for physical barriers for privacy and discretion. At the same time, stigma and shame can be obstacles to interaction, requiring tactfully designed settings to bridge gaps and break barriers.

\section{Discussion and Conclusion}

Our study confirms the value of photovoice as a suitable method to extricate spatial aspects from people's personal experiences even in sensitive contexts. The act of documenting their experience with photographs blurs the boundary between researcher and participant. Participants willing to adopt photovoice may not be representative of all cancer patients. However, by documenting their experience with photos, participants made visible a CCE that exceeds the hospital boundaries. Further research is necessary to explore the extent of the differing descriptions of the CCE based on the perspectives of other users, healthcare providers and CCE designers.

Awaiting this exploration, our analysis of the interviews and photos shows participants' experience changing over time and across space as repeated travel between the home and hospital, and transitions within the hospital result in new impressions and routines. Photovoice allowed the researchers to question what spaces are considered part of the CCE. This aspect of the findings would likely not have come forward without this visual method that allowed participants to bring topics and their own focus to the interviews. Additional findings relate to how the body, changing as a result of treatment, affects perception and experience of the environment. Social interactions are affected by cancer demanding that the CCE takes issues of shame into account.

We recognise that the initial experience of cancer is one where all sense of normality is temporarily lost (Vollmer and Koppen 2010). A supportive hospital environment can help regain some of this and become through routine - as it was for Lisa - like a "second home". Much in this analysis is brought together in the idea of normalization. The types of activities that participants valued during their hospital visits point towards regaining a sense of normalcy in their life. The environment can afford the opportunity to choose (furniture/ seating type), initiate (closing curtains, taking coffee) and take some control or ownership (knowing where to find blankets) instead of users being fully reliant on others. Cresswell finds that a focus on place 
can act to normalize and naturalise identity through a shared geographical location (Cresswell 2004). Identity can be constructed through the shared experience of place rather than (or instead of) a stigmatising feature that the people coming together in that place have in common. If we relate this to the success of the Maggie's Centres there is evidence that architecture's potential is also in supporting a collective experience (Van der Linden et al. 2015), possibly alleviating some of the current stress around confrontation, and facilitating informal interactions.

This study supports previous findings with reference to the hospital being conceived as a type of 'home'. In looking closely at contesting meanings associated with hospital spaces Kellett and Collins $(2009,114)$ find that the "uneasy relationship between home and hospital" is at the heart of a battle. Their study discusses the domestication of the hospital by examining ways in which a hospital space may be (re)constructed as 'home' by those occupying it. Although it is unusual to associate 'home' with an institutional building it is fitting to consider the concept of home as a polar opposite to the typical hospital (Kellett \& Collins 2009). Participants use these archetypical concepts to compare and evaluate their experience of spaces. At the same time it is in referencing one's particular 'home' that personality, taste and other personal features result in diverse responses.

In terms of implications for hospital design, we see a particular challenge to improve the initial experience. There may be options to de-medicalize a consultation environment, creating a pleasant atmosphere to enter into. Designing hospitality is key, with clear signage, sufficient seating options and thoughtful attention to privacy needs for those receiving difficult news. This supports Vollmer and Koppen's (2010) conclusion in their design research in which they emphasised the need to architecturally link medical and psycho-social care for outpatient cancer care.

Our findings suggest that patients could be further supported by a diversification of activities offered within the hospital. Participants indicated an interest in aspects of the environment that offer or support distraction, (social) contact, information, relaxation and other daily activities. What one expects and needs in the hospital is influenced by the home and household situation - in terms of the location and distance to where the cancer care takes place; but also in relation to other household members and their availability to offer practical and emotional support. Again, this points towards a desire to have psycho-social care and support integrated with medical care. Healthcare professionals tend to see psychosocial care and medical care (treatments etc.) as separate while participants in this study suggested, that in their experience these are (expected to be) fully integrated.

Lastly, it became necessary to see participants' homes as links in a concatenation of places that together form an individual's experience of the CCE. Increasingly, chemotherapy treatments are becoming available which can be self-administered at home (Bloom et al. 2015). For example, in Belgium, 12 pilot projects for 'home hospitalisation' were recently approved, six specifically for cancer care (De Block 2017). Our findings suggest that this indeed forms an extension of contemporary cancer care, whereby the home is transformed to a place of medical care. However, caution is required, as the patient can feel insecure and far removed from the watchful eye of the medical specialists. 
P. Jellema et al.

\section{Acknowledgements}

We are grateful to the three participants who generously gave of their time and energy for this study. This project was realized with the support of Kom op tegen Kanker (Suzanne Duchesne Fund) and Research Fund KU Leuven (PDM/16/092).

\section{References}

Annemans, M., Van Audenhove, C., Vermolen, H., \& Heylighen, A. (2012). What makes an environment healing? In Out of control. 8th International Design and Emotion Conference Proceedings (p. 8). London.

Bloom, M., Markovitz, S., Silverman, S., \& Yost, C. (2015). Ten Trends Transforming Cancer Care and Their Effects on Space Planning for Academic Medical Centers. HERD, $8(2), 85-94$.

Cresswell, T. (2004). Place: a short introduction. Malden, MA: Blackwell Pub.

De Block, M. (2017). Twaalf pilootprojecten rond thuishospitalisatie in de startblokken [Press report 09/03/2017] Retreived August 18, 2017, from www.deblock.belgium.be

Dierckx de Casterlé, B., Gastmans, C., Bryon, E., \& Denier, Y. (2012). QUAGOL: A guide for qualitative data analysis. International Journal of Nursing Studies, 49(3), 360-371.

Frith, H., \& Harcourt, D. (2007). Using photographs to capture women's experiences of chemotherapy. Qualitative Health Research, 17(10), 1340-1350.

Guba, E. G., \& Lincoln, Y. S. (1994). Competing Paradigms in Qualitative Research. In Handbook of qualitative research, Eds.: Norman K. Denzin, Yvonna S. Lincoln (pp. 105117). Sage.

Huisman, E., Morales, E., van Hoof, J., \& Kort, H. S. M. (2012). Healing environment. Building and Environment, 58, 70-80.

Jencks, C. (2012). Can architecture affect your health? Arnhem: ArtEZ Press.

Kellett, P., \& Collins, P. (2009). At home in hospital? Competing constructions of hospital environments. ArchNet-IJAR, 3(1), 101-116

Kirkeby, I. M. (2015). Accessible Knowledge-Knowledge on Accessibility. Journal of Civil Engineering and Architecture, 9(5).

Lawson, B., \& Parnell, R. (2015). Quality of place and wellbeing. In Oxford Textbook of Creative Arts, Health, and Wellbeing (pp. 299-308). Oxford University Press.

Malkin, J. (2006). Healing Environments as the Century Mark. In C. Wagenaar (Ed.), The architecture of hospitals (pp. 259-265). Rotterdam: NAi Publishers.

Radley, A. (2010). What people do with pictures. Visual Studies, 25(3), 268-279.

Rubin, H. R., Owens, A. J., \& Golden, G. (1998). An investigation to determine whether the built environment affects patients' medical outcomes. Martinez, CA: The Center for Health Design.

Sternberg, E. M. (2009). Healing spaces: the science of place and well-being. Cambridge, Mass: Belknap Press of Harvard University Press.

Ulrich, R. S. (1984). View through a window may influence recovery from surgery. Science, 224(4647), 417-419.

Van der Linden, V., Annemans, M., \& Heylighen, A. (2015). "You'd want an energy from a building”. In Proceedings of the Third European Conference on Design4Health 2015.

Vollmer, T., \& Koppen, G. (2010). Architectuur als tweede lichaam. Layout 11, Stimuleringsfonds Creatieve Industrie, 1-16.

Wang, C., \& Burris, M. A. (1997). Photovoice: Concept, Methodology, and Use for Participatory Needs Assessment. Health Education \& Behavior, 24(3), 369-387. 